\title{
Using preference, motivation and aversion tests to ask scientific questions about animals' feelings
}

\author{
Richard D. Kirkden ${ }^{\mathrm{a}}$, Edmond A. Pajor ${ }^{\mathrm{b}, *}$ \\ a Animal Welfare Program, Faculty of Land and Food Systems, University of British Columbia, \\ 2357 Main Mall, Vancouver, BC, Canada V6T $1 Z 4$ \\ ${ }^{\mathrm{b}}$ Department of Animal Sciences, Center for Food Animal Well-Being, Purdue University, \\ Poultry Science Building, 125 South Russell Street, West Lafayette, IN 47907-2042, USA
}

Available online 11 May 2006

\begin{abstract}
The past 30 years has seen an increased willingness for scientists to assess the subjective experiences of animals. There are good reasons to believe that domesticated animals are sentient beings, capable of having feelings. The study of feelings is central to the assessment of animal welfare. Feelings are not directly observable, but have measurable correlates or consequences. They can be assessed either by giving animals some control over their environments and observing the choices and decisions they make, using preference and motivation tests (including aversion tests), or by looking for signs of deprivation, frustration or distress when the animal is confined in an environment or subjected to a treatment without any means of control. Preference and motivation tests assess motivation, defined operationally as the tendency for an animal to perform a behaviour, but understood as reflecting the animal's desire to do so. These tests are used to address four distinct research questions: (1) whether an animal is motivated to obtain or avoid a resource; (2) whether it has a preference amongst alternative resources (i.e., whether it is more motivated for one than the other); (3) how strong its motivation or preference is and (4) whether its preference, or the strength of its motivation or preference, is altered by changes in its internal or external environment. Methods that have been used to answer these questions fall into two overlapping categories: choice tests and operant tests. A wide array of such tests has been employed, each with its own strengths and weaknesses. We describe individual methods, indicating the research questions they have been designed to address, list their limitations and discuss methodological problems that are not yet fully resolved. Preference and motivation tests are techniques that are still under development. However, if carefully interpreted and properly integrated with other measures of welfare, they constitute a powerful tool for the assessment of welfare. (C) 2006 Elsevier B.V. All rights reserved.
\end{abstract}

Keywords: Preference, Motivation, Aversion, Feelings, Operant tests, Choice tests

This paper is part of the special issue entitled Sentience in Animals, Guest Edited by Dr. John Webster.

* Corresponding author. Tel.: +1 765496 6665; fax: +1 7654949347.

E-mail address: pajor@purdue.edu (E.A. Pajor). 


\section{Introduction}

Although the scientific investigation of animal feelings, defined here as affective states, dates back at least to Darwin, a reluctance to consider subjective experiences developed in the late 19th and 20th century as a manifestation of positivism. Positivists attempted to create a clear separation between science and metaphysics by excluding unobservable processes from scientific inquiry (Rollin, 1990; Fraser, 1999). Positivism influenced psychology, where it led to behaviourism. It also influenced some of the pioneers of ethology (Burkhardt, 1997). For example, Tinbergen (1951) wrote:

"Because subjective phenomena cannot be observed objectively in animals it is idle to either claim or to deny their existence."

As a result, both behaviourists and many ethologists took the view that the subjective experiences of animals have no place in scientific explanation.

The past 30 years has seen a renewed willingness to use scientific methods to understand the subjective states of animals (Duncan, 1970; Griffin, 1976; Cabanac, 1979; Dawkins, 1980) and has led to the development of numerous scientific approaches to understanding the emotional states of animals and assessing their welfare.

The direct observation of an animal's subjective experiences is not possible. However, there are good reasons to presume that feelings exist in many non-human species, including domesticated animals. Similarities across vertebrate species in their neural anatomy and their behavioural and physiological responses to stimuli that elicit feelings in humans strongly suggest a widespread capacity for feelings (Dawkins, 1980; Toates, 1987).

Fraser et al. (1997) describe three conceptions of animal welfare that have been proposed or implied by scientists. These define animal welfare in terms of feelings, functioning of the body and ability to express natural behaviours, respectively. These different conceptions influence the criteria for variables used by scientists, and ultimately the overall assessment of an animal's welfare. Different animal welfare scientists and philosophers emphasise different concepts, or combinations of them. Most consider feelings to be an important aspect of welfare (e.g., Fraser et al., 1997; Broom, 1998) and some regard them as the sole criterion of welfare (e.g., Duncan, 1996). Individuals who emphasise natural behaviour or functioning may believe that feelings are irrelevant, unmeasurable, or so closely correlated with other welfare measures that their assessment is redundant. The first is a rather singular claim, at odds with most ethical views, the second is a positivist stance and the third is demonstrably false (see Fraser et al., 1997).

Whilst it cannot be proven that feelings play a role in the causation of behaviour, even in humans (Fraser and Duncan, 1998), it is widely suggested or assumed that at least some affective states do play a role (e.g., Broom, 1998; Fraser and Duncan, 1998) and hence that they have observable effects (Dawkins, 1993). Even if feelings do not have observable consequences, the correlation between reported feelings and behavioural responses to stimuli in humans (e.g., Cabanac, 1979) suggests that behavioural and physiological responses reflect the strength of associated feelings.

\section{Feelings are linked to motivation and preference}

Scientific definitions of motivation tend to be operational: if an animal is motivated to do something, this means it is likely to. Thus, for example, scientists define motivation as 'the process within the brain controlling which behaviours and physiological changes occur and 
when' (Fraser and Broom, 1990) or 'a construct used to describe the strength or willingness with which an animal engages in behaviour' (Toates, 1986, p. 7). In contrast, in everyday speech we often equate motivation with feelings. For example, when we are motivated to drink we may describe ourselves as thirsty, or when motivated to flee we may describe ourselves as afraid. These approaches are not mutually exclusive and some motivational theorists have combined them in hedonic models of motivation (e.g., Young, 1959; Herrnstein, 1977; Toates, 1987; Cabanac, 1992).

Animal welfare scientists also make use of both types of definition. Operational definitions are useful, because they link motivation to a measurable outcome. However, the objective is to find out what things animals want and how much they want them. Formally, animal welfare scientists may take the position that animals generally have subjective experiences of their motivations. Thus a motivation to feed, defined formally as a tendency to feed, is said to be accompanied by hunger. Many take the stronger view, either implicitly or explicitly, that feelings are the motivations that cause most behaviour to occur and when the term 'motivation' is used it is often intended to refer to desires.

Motivations can be positive, for example, the desire to consume a commodity or perform a behaviour (the term 'resource' will be used hereafter to refer to both of these outcomes), or negative, for example, the desire to avoid a painful or frightening stimulus. Positive and negative motivations are also known as appetitive and aversive (or defensive) motivations (e.g., Konorski, 1967, p.10; Masterson and Crawford, 1982; Lang et al., 1990). In operational terms, they describe the tendency to approach or avoid resources and stimuli, respectively. It should be noted that this classification of motivations does not map in a simple way onto positive and negative feelings (Berridge, 1996; Fraser and Duncan, 1998). For example, feeding motivation may involve both negative feelings (hunger) and positive feelings (sensory pleasure).

Motivations can also vary in strength. When animal welfare scientists study motivation, they are often interested in finding out how strong it is. This is because if an animal is strongly motivated to do something, but the environment in which it is kept prevents it from doing so, then its welfare is likely to be poor (Dawkins, 1990).

The term 'preference' denotes a difference between the strength of motivation to obtain or avoid one resource or stimulus and the strength of motivation to obtain or avoid another. It is distinct from the term 'choice' in that it describes characteristics of animals (e.g., this animal prefers bananas to oranges), whereas choice is an operational term describing instances of behaviour (e.g., the animal chose to turn right rather than left). Moreover, one can speak of preferences only in cases where the resources are alternatives. The term 'alternatives' has two possible meanings in this context. The resources could be alternatives from the animal's point of view, i.e., different ways to satisfy the same positive motivation (termed 'substitutes'), or contributing to a common negative motivation. Arguably, a preference between non-substitutes has little meaning from an animal's point of view, for example, a preference for food over litter, since the animal would prefer food for eating, but litter for resting. Here, the comparison is not really between resources, but between the strengths of different motivations. Alternatively, the resources could be alternatives from the animal user's point of view; for example, where it is decided that the animal will be given access either to one resource or the other, but not to both. In this case, alternative resources that satisfy positive motivations need not be substitutes. These two definitions have different implications for the kinds of resources that are compared in tests of preference, and for the methods that are used to compare them. When animal welfare scientists refer to preference tests (e.g., Duncan, 1992; Fraser and Matthews, 1997), the methods that are usually described (simple choice tests) are suited to the comparison of substitutes rather than 
non-substitutes (see below). Thus, the narrower definition of alternatives, which refers to substitutes, would bring the term 'preference' into line with the usage of 'preference tests'. However, the broader definition, that includes non-substitutes, is probably more consistent with the general use of the term 'preference'. Preference will therefore be defined here as the difference between motivations for alternatives, where 'alternatives' will be taken to mean either substitutes or non-substitutes.

\section{Assessing feelings}

There are two main approaches to assessing feelings. One approach involves giving the animal some control over its environment and observing the decisions it makes. The other involves observing the animal's responses when it is confined in an environment or subjected to a treatment without any means of control.

In the first approach, feelings associated with obtaining desired resources and avoiding unpleasant stimuli are investigated using procedures known as preference tests, motivation tests and aversion tests. These procedures will be the focus of this paper.

Preference tests focus upon choices made between alternative resources or stimuli and simply rank them, whereas motivation tests quantify the strength of motivations and do not necessarily give animals choices (Fraser and Matthews, 1997). A key feature of motivation tests is that the animal is required to pay a cost of some kind (e.g., operant 'work' or loss of another resource) to gain access to or consume the resource of interest (Duncan, 1992; Fraser and Matthews, 1997), but this is not sufficient to ascertain whether motivation is strong. In order to quantify the cost to the animal (e.g., how hard it perceives a given amount of operant responding to be) it is also necessary to use as a comparator a resource of known value and, when comparing positive motivations, to use a comparator that is not a substitute for the resource of interest. For example, a comparison between bedding and social contact cannot reveal whether motivation for bedding is strong if the value of social contact is unknown, nor can a comparison between foodstuffs of low and high palatability reveal whether motivation for either of the foodstuffs is strong. Thus, motivation tests should proceed by comparing the resource of interest with a non-substitute of known value.

A related way to classify preference and motivation tests is in terms of the type of research question they are designed to answer. There are four distinct questions:

(1) whether an animal is motivated to obtain or avoid a resource;

(2) whether it has a preference amongst alternative resources;

(3) how strong is its motivation or preference;

(4) whether its preference, or the strength of its motivation or preference, is altered by changes in its internal or external environment.

This classification extends the accepted dichotomy between preference tests and motivation tests. Methods used to address question (2) often give animals choices and in this case would be defined as preference tests, while procedures used to address question (3) would be termed motivation tests. However, the methods used to address questions (1) and (4) are more difficult to fit into this dichotomy because these methods do not quantify motivational strength and do not necessarily give animals choices. Cases where question (2) is addressed without giving animals choices (e.g., where the alternatives are not substitutes) are also exceptions; here a preference is assessed without using a 'preference test'.

Cutting across the operational distinction between preference and motivation tests, a distinction is also made between tests of aversion and tests of positive motivation. Aversion tests 
investigate negative motivations. They can focus either upon choices between stimuli, or upon the measurement of motivational strength (Rushen, 1996) and may be regarded as a subset of preference and motivation tests (Fraser and Matthews, 1997). To assist with classification, preference and motivation tests that investigate positive motivations will be termed 'appetence tests'. Appetence is defined in the Oxford English Dictionary as 'the action of seeking for or longing after'. In psychology, the terms 'appetence', 'appetency' and 'appetition' have been used interchangeably to refer to appetitive motivations and to distinguish them from aversion (e.g., Baldwin, 1901; Dussault, 1996; Cacioppo and Berntson, 1999; Gable et al., 2003).

Because feelings are not directly observable, their assessment is always a two-part process. One part involves measuring a behavioural or physiological response; the other involves interpreting the response (Kirkden et al., 2003). Thus, preference and motivation tests can also be classified according to the kind of response that is measured and the way responses are interpreted.

In terms of the kind of response that is measured, these tests are often classified into choice tests and operant tests. Choice tests, as the name suggests, give animals choices between different environments or resources. All preference tests and some motivation tests are choice tests. Operant tests train animals to perform or refrain from performing responses such as lever pressing for access to desired outcomes. These include most motivation tests. In practice, there is a fair amount of overlap between these procedures, since some choice tests incorporate operant responding. In terms of the four types of research question listed above, questions (1) and (2) are most often addressed by choice tests, while questions (3) and (4) are most often addressed by operant tests. Hence, the classifications by kind of response and research objective tend to converge.

Finally, preference and motivation tests can also be classified in terms of the way the measured responses are interpreted. The interpretation of appetence tests designed to answer questions (1), (4) and in many cases (2), as well as the interpretation of aversion tests, tends to be relatively straightforward, because the resources or stimuli of interest address a single positive motivation, or are assumed to contribute to a common underlying negative motivational state (Rushen, 1990). Such tests will be called 'single-motivation' appetence tests and aversion tests. The interpretation of appetence tests designed to answer question (3), and in some cases question (2), can be more complex, due to the comparison of different motivations, and is presently the subject of some controversy. These will be termed 'between-motivations' appetence tests. The differences between these tests will be illustrated later.

In the second approach to measuring feelings, the animal is simply put in an environment containing or lacking certain stimuli and its responses are observed. Feelings associated with being unable to obtain desired resources are investigated by placing the animal in an environment that lacks the resource and looking for signs of deprivation or frustration, such as redirected behaviours, stereotypes and physiological stress responses. Feelings associated with being unable to avoid unpleasant stimuli are studied by exposing the animal to the stimulus and looking for signs of fear or distress, such as escape attempts and physiological stress responses.

The two approaches complement one another. Preference and motivation tests have several strengths compared with measures of deprivation, frustration and distress. First, they are more sensitive than some measures of deprivation and frustration, since bad feelings do not always result in major behavioural disturbances such as redirected behaviour and stereotypy. Second, as Dawkins $(1988,1990)$ has pointed out, motivation tests are able to quantify the strength of feelings, whereas it is unclear how much abnormal behaviour or physiological stress must be shown before feelings can be said to be strong. 
However, appetence tests also have an important weakness that measures of deprivation and frustration are capable of addressing. When deciding whether to gain access to a resource, motivation is invariably influenced by cues emanating from the resource or associated with it. Hence, appetence tests may overestimate the strength of an animal's feelings compared with an environment in which the resource is absent and unavailable, where out of sight may be out mind (Petherick et al., 1990b; Warburton and Mason, 2003). Measures of deprivation and frustration are an important tool to explore this possibility.

\section{Single-motivation appetence tests}

\subsection{Choice tests}

In a single-motivation choice test, an animal may be required to make a series of discrete choices between alternative environments or resources, often using a T- or Y-maze (e.g., Dawkins, 1977, 1983; Petherick et al., 1990a). Alternatively, it may be allowed to divide a fixed amount of time between the alternatives (e.g., Hughes and Black, 1973; Dawkins, 1977; Nicol, 1986). The resource that the animal chooses more often, consumes in a greater quantity, or spends more time with, is said to be preferred. Studies of this kind can ascertain whether an animal is motivated to obtain a resource $(\mathrm{Q} 1)$, by offering a choice between the resource and no resource. They can also identify a preference between two different resources (Q2).

However, single-motivation choice tests have a number of limitations. First, motivation and preference depend on context. Both external and internal variables must be considered. For example, ambient temperature determines whether pigs prefer straw bedding over bare concrete for lying (Q4, Fraser, 1985), while female rats prefer access to a male over another female only when in oestrus (Gilman and Westbrook, 1978). Second, preference depends on experience. Animals may initially prefer environments they are used to (Dawkins, 1977). Third, care must be taken when offering discrete choices, since access times may not coincide with times of peak motivation (Fraser and Matthews, 1997). Fourth, when attempting to identify a preference amongst resources (Q2), it may be difficult to interpret non-exclusive choices, in which subjects do not allocate all of their choices or time to a single resource. The resource that is chosen more is not necessarily preferred. In some cases, preference may fluctuate in response to a changing external variable, for example, pigs prefer to rest on straw in the morning when it is cold, but not in the evening when it is warmer (Steiger et al., 1979). In other cases, a non-exclusive choice may occur because the different resources have different uses or properties. For example, a large cage might be preferred for exercise while a small cage is preferred for nesting. This is the most important limitation of single-motivation appetence tests. A preference can only be established among resources that are unidimensional substitutes, i.e., those that differ along a single motivational dimension (Nicol, 1997).

\subsection{Operant tests}

Single-motivation operant tests typically give animals access to only one environment or resource of interest at a time, the starting location serving as a reference or control environment. Subjects are required to perform a response for access, such as pressing a lever. If the response is acquired, this demonstrates that a motivation exists (Q1: e.g., Baldwin and Start, 1981; Dawkins and Beardsley, 1986; Hutson, 1989). Moreover, the greater the number of responses performed, the stronger motivation is said to be. Occasionally this method is used to compare different 
resources presented serially, in order to ascertain a preference (Q2). More often it is used to compare the strength of motivation for a single resource before and after some change in the environment (Q4: e.g., Lawrence et al., 1989; Arey, 1992).

Single-motivation operant tests have several limitations. As with single-motivation choice tests, motivation depends on context and experience. There is also concern that an innate predisposition to associate responses (e.g., pecking) with particular outcomes (e.g., food rewards) may render operant tasks easier to learn for access to some resources than others (Dawkins and Beardsley, 1986). One further limitation applies when attempting to assess a preference between different resources (Q2). Measures of the number of rewards earned can be misleading when used to assess preference between non-substitutes, because different resources are often required in very different quantities to satisfy their respective motivations. A similar problem applies when comparing substitutes that are not available concurrently: the alternatives may be required in different quantities to satisfy a common motivation. If only one resource is available, then a need to satisfy the motivation, using whatever quantity of the resource is necessary, may obscure the subject's preference for how to satisfy it. For this reason, it is preferable to make resources that are substitutes available concurrently (Sørensen et al., 2001, 2004). An operant test employing concurrent schedules can be used (e.g., Sørensen et al., 2001, 2004), in which the subject is required to perform a discrete response for access to each of several alternative resources. However, it is not clear that this has any merit over a simple, single-motivation choice test.

\section{Between-motivations appetence tests}

Single-motivation appetence tests must be modified to allow the assessment of preference between multidimensional substitutes, or non-substitutes (Q2) and to measure the strength of motivation or preference $(\mathrm{Q} 3)$. The modifications required to address these two research questions are similar. First, in order to measure the strength of motivation or preference, it is necessary to compare resources that satisfy different motivations (i.e., resources that are not substitutes) and the strength of motivation for the comparator must be known a priori. For example, Dawkins (1983) compared motivation for access to litter in hens with motivation to feed at various hunger levels. Second, when comparing resources that are either multidimensional substitutes or non-substitutes, a simple measure of response magnitude, such as the number of times a resource is chosen, the amount of time spent with it, or the quantity consumed, is not a valid measure of motivation or preference. This is because different motivations may satiate at different rates and may require very different quantities of their respective resources (e.g., drinking versus nest-building; lying in straw versus foraging in straw). It is necessary to employ a measure that is independent of the magnitude of resource use. A number of measures have been proposed, most of which can be understood as estimates of how much an animal is willing to pay for access to a resource.

Between-motivations appetence tests retain all of the limitations that apply to singlemotivation appetence tests, except that their modifications enable them to compare resources that are not unidimensional substitutes. Moreover, different approaches vary in the types of resources they are best suited to comparing and in their general validity.

\subsection{Operant tests}

The most straightforward approach and the least problematic employs an ascending series of schedules, in which the cost of access to the resource is increased from one experimental session to the next. Cost may be manipulated by increasing the number of responses required (the fixed 
ratio or FR schedule), or increasing the amount of effort required to make a single response, such as when pushing through a weighted door. The highest schedule that the subject completes is a direct measure of how much it is willing to pay for a single visit, known as the reservation price or the highest price paid (e.g., Manser et al., 1996; Mason et al., 2001; Olsson et al., 2002; Kirkden and Pajor, in press). It estimates the value that the animal attaches to access to the resource after a specific period of deprivation (Kirkden et al., 2003), determined by the session duration and the period between sessions.

A measure that is sometimes confused with the reservation price (e.g., Matthews, 1998) is the break point. The break point is the highest schedule that the subject completes on a progressive ratio (PR) schedule, in which FR is increased after every reward during the course of a single session. This approach may fail to measure motivation independently of resource use, since the subject may approach satiation during the session.

The reservation price index is a special case of a family of measures known as the consumer surplus (e.g., Mason et al., 2001). Consumer surplus measures are obtained from a demand curve, which is a plot of demand (number of rewards earned) against price (FR schedule). They correspond to areas under the demand curve, with boundaries on the demand axis (see Kirkden et al., 2003). A particular consumer surplus area estimates how much an animal is willing to pay for access to a specific quantity of a resource (e.g., to a single measured reward during the course of a day, or to the first 10 rewards, or to a satiating quantity), or for access to a single reward at a specific level of prior consumption (e.g., to the 10th reward of the day). The advantage of working with a demand curve is that is possible to evaluate multiple quantities or prior consumption levels using a single data set. However, the demand curve approach is not suitable for all resources. In order to generate a valid demand curve, it is necessary to hold reward size constant, but doing so may devalue some resources, such as access to a social partner (Mason et al., 1998). Demand curves also yield approximate measures of willingness to pay, because the income effects of price changes are ignored (Kirkden et al., 2003). The consumer surplus has sometimes been measured incorrectly, with boundaries on the price axis instead of the demand axis (e.g., Sherwin, 2004; Jezierski et al., 2005), and its ability to distinguish between quantities or prior consumption levels has not yet been exploited.

A more widespread measure, that is also obtained from a demand curve, is the price elasticity of demand (e.g., Matthews and Ladewig, 1994; Sherwin and Nicol, 1997; Mason et al., 2001), defined as the slope of a plot of the log of demand against the log of price. The slope of the untransformed demand curve has also been used (e.g., Cooper and Appleby, 1996; Sherwin and Nicol, 1996; Warburton and Nicol, 2001), but is less valid, since the bilogarithmic transformation converts absolute changes into proportional changes, rendering them independent of the units in which demand and price are measured. The elasticity of demand approach assumes that the slope of the bilog curve is linear and proposes that the shallower the slope, the stronger the animal's motivation for access to the resource. If demand changes little as price increases, the animal is said to be prepared to work hard to defend some preferred consumption level. Some researchers have suggested absolute cut-off points for the price elasticity or slope of the demand curve, below which a resource is said to be highly valued without referring to a comparator, for example, a price elasticity of less than 1 (e.g., Matthews and Ladewig, 1994; Holm et al., 2002), or a slope not significantly different from zero (e.g., Cooper and Appleby, 1996; Sherwin and Nicol, 1996).

The elasticity of demand approach has a number of limitations. First, it employs a demand curve, which means it is not suitable for all resources and is subject to inaccuracies arising from income effects. Second, the assumption that the bilog curve is linear is frequently violated (Hogan and Roper, 1978; Hursh et al., 1988; Foster et al., 1997; Sumpter et al., 1999). Variants on 
the price elasticity of demand have been used to interpret non-linear bilog curves, including point elasticity values obtained at specific prices (Jensen et al., 2004b) and a measure known as $P_{\max }$, defined as the price at which work done reaches a maximum (Patterson-Kane et al., 2002). Third, this approach seeks to assign a single value to each resource, ignoring the effects of prior deprivation or consumption and quantity available, which is not realistic. Fourth, it fails to measure motivation independently of resource use, since the slope of the curve is influenced by its starting height. Fifth, it is not clear that it measures motivation at all, since the slope of the bilog demand curve may instead reflect the rate at which satiation occurs (Kirkden et al., 2003). Sixth, the use of absolute cut-off points is not valid. The price elasticity of demand is influenced by procedural variables such as reward size (Matthews and Chandler, 1996; Jensen et al., 2004b,c) and the type of operant task (Sumpter et al., 1999; Hansen et al., 2002) and for a given resource it can vary widely between studies. For example, the price elasticity of demand for food has been found to range from 0.02 (pigs pressing a nose-plate for access to $27 \mathrm{~g}$ rations of their normal pelleted diet: Matthews and Ladewig, 1994) to 1.10 (mink pulling a chain for access to $0.5 \mathrm{~g}$ rations of their normal meat paste diet: Hansen et al., 2002). Moreover, practically every resource that has been evaluated in an operant test exhibits a price elasticity of demand below 1 . A survey of the literature found 16 studies (Matthews et al., 1993, 1995, 1998; Matthews and Ladewig, 1994; Ladewig and Matthews, 1996; Matthews and Chandler, 1996; Sherwin and Nicol, 1997; Gunnarsson et al., 2000; Hansen et al., 2002; Holm et al., 2002; Ladewig et al., 2002; Pedersen et al., 2002; Jensen et al., 2004a,b,c; Sherwin, 2004) that had obtained correct measures of the price elasticity of demand for a total of 50 resources. Of these, only one resource exhibited a demand elasticity greater than 1 . This was the case cited above, of demand for food in mink (Hansen et al., 2002). In all other cases, demand elasticity was less than 1, even demand for a $15 \mathrm{~s}$ view of an inaccessible empty pen, which had a price elasticity of 0.63 (Matthews and Ladewig, 1994)! It seems clear that an elasticity value of 1 is not a useful cut-off point.

\subsection{Choice tests}

Between-motivations choice tests are used less frequently than between-motivations operant tests. Because they present resources concurrently, they are particularly suitable for the assessment of preferences (Q2). However, when measuring the strength of a motivation or preference (Q3), it is often inadvisable to make several resources of interest available concurrently, since the availability of one resource may influence the value of another.

A straightforward modification to a choice test that may free responding from the magnitude of resource use is to use widely spaced discrete trials (e.g., Hughes, 1975). This ensures that during a period in which the subject is motivated for two different resources, only one can be chosen. The resource that is not chosen is effectively 'spent' on the other. Moreover, by presenting choices between one location containing a fixed quantity of the resource of interest and another containing a variable quantity of the comparator, it should be possible to measure how much of the comparator the subject is willing to spend on this quantity of the resource of interest.

A limitation of this approach is that even with widely spaced trials non-exclusive choices might occur. One reason could be that the time course of deprivation exceeds the spacing between trials, so that the animal is able to avoid maximal deprivation for one or both resources by choosing them alternately.

Another approach has been to impose a variable cost on resource consumption (as opposed to access) and to use a variant on the price elasticity of demand. Costs include exposing the animal 
to an unpleasant stimulus while interacting with the resource of interest (e.g., Faure and Lagadic, 1994), or inducing a state of deprivation for the comparator (e.g., Dawkins, 1983). The time spent with the resource (expenditure), or the quantity consumed (demand), is plotted against price to obtain a demand curve or an analogue of one. Imposing a cost upon consumption rather than access avoids the need to hold reward size constant, but for the demand curve to be valid it is necessary to verify that the rate of resource use does not increase with price.

Other methods have also been used to impose a variable cost on access or consumption, yielding variants on a measure known as the income elasticity of demand, defined as the slope of a plot of the log of demand against the log of income. For example, session duration (income) may be reduced (Dawkins, 1983; Warburton and Nicol, 2001), or an operant task may be used to impose a uniformly increasing cost on access to all resources. The latter method has frequently been interpreted as an increase in price (e.g., Sherwin, 1996; Sherwin and Nicol, 1996; Cooper and Mason, 2001; Mason et al., 2001; Warburton and Mason, 2003), but it in fact leaves relative prices unchanged and constitutes a reduction in income (Lea, 1978, p. 456; Varian, 1996, p. 25). The income elasticity of demand is interpreted in the same way as the price elasticity of demand and has the same limitations, except that income effects do not apply (Kirkden et al., 2003). In the approach where access cost is increased, reward size must be held constant, whereas in cases where session duration is reduced, it must be verified that the rate of resource use does not vary.

\section{Aversion tests}

Aversion tests designed to assess whether a preference exists (Q2), or to measure the strength of a motivation or preference (Q3), do not require the same level of complexity as appetence tests. This is because the difficulties involved in comparing resources that satisfy different positive motivations probably do not apply to negative motivations. It is assumed that all negative stimuli contribute to 'distress', a common motivational state underlying the specific states of fear, pain, anxiety, frustration and boredom (Rushen, 1990). This means that any state can be compared with any other. Furthermore, since animals do not satiate differentially (or at all) for different negative states, a simple comparison of response magnitudes is sufficient. Hence, in aversion tests, there is much less distinction between procedures designed to ascertain whether a preference exists (Q2) and those designed to measure the strength of preference (Q3).

\subsection{Choice tests}

Choice tests designed to ascertain whether an animal is motivated to avoid a stimulus (Q1), or to identify a preference between two different stimuli (Q2), are often very similar to singlemotivation choice tests designed to investigate positive motivations and preferences. The stimulus that is chosen fewer times (e.g., Rushen, 1986b; Abeyesinghe et al., 2001a; Pajor et al., 2003), or with which less time is spent (e.g., Raj and Gregory, 1991; Jones et al., 1996; Sherwin, 1999), is said to be more aversive. If enough is known a priori about the aversiveness of the comparator (e.g., electric shock: Rushen, 1990), then conclusions can also be drawn about the strength of aversion (Q3).

Alternatively, choice tests can be modified to measure the strength of an aversion relative to motivation for access to a positive comparator. In this approach, the subject is offered a choice between one location in which the negative stimulus and positive comparator are both present and another location in which they are both absent. If the negative stimulus is more aversive than the comparator is attractive, then the animal will avoid both (e.g., Cooper et al., 1998; Jones et al., 
1999; Raj and Mason, 1999). Some studies have presented different quantities of the comparator in the two locations (e.g., Phillips and Morris, 2001), but the principle is the same.

Like single-motivation choice tests used to assess positive motivations and preferences, choice tests used to measure aversion have several limitations. Their findings are influenced by context and experience. Also, non-exclusive choices may be difficult to interpret, since they could be caused by fluctuations in the animal's internal or external environment.

\subsection{Operant tests}

Because negative stimuli are not substitutes, in the sense that exposure to one does not increase satiation for the other, a preference signifies nothing more than a difference in motivation and there is no need to present alternative stimuli concurrently. Accordingly, operant tests are used at least as often as choice tests to investigate preferences.

As in single-motivation appetence tests, subjects may be required to perform a response, such as pressing a lever or traversing a runway, to avoid exposure to a stimulus (e.g., Stephens et al., 1985; Rutter and Duncan, 1991). If the response is acquired, this demonstrates that the stimulus is aversive (Q1). Furthermore, if the response magnitude is greater for one stimulus than another, then the former stimulus is more aversive (Q2).

Alternatively, a passive avoidance procedure may be used, in which the animal is first trained to perform a response for access to a positive resource, then the stimulus of interest is substituted for this resource, or paired with it, and the decline in responding is measured (e.g., Petherick et al., 1992; Rutter and Duncan, 1992; Jones et al., 1998). In a common variant, subjects are forced to traverse a runway without having been trained to perform the response and their reluctance to move is measured (e.g., Rushen and Congdon, 1987; Hargreaves and Hutson, 1990; Pajor et al., 2000).

The same procedures can also yield information about the strength of aversion (Q3), for example, by pairing the negative stimulus with a positive resource and looking for a substantial or complete loss of responding (e.g., Randall et al., 1997; Jones et al., 1998; Abeyesinghe et al., 2001b), or information about the effect of changes in the internal or external environment upon the strength of aversion (Q4: e.g., Hutson, 1985; Stephens et al., 1985; Hargreaves and Hutson, 1990).

The limitations of operant tests used to assess aversion include the effects that context and experience have upon motivation. Also, animals may be innately predisposed to respond in different ways to different stimuli. Thus, where a freezing response is normal, a passive avoidance task would be readily learned, whereas in cases where an active response is normal, an active avoidance task might be more appropriate (Rutter and Duncan, 1992). In active avoidance tests, preferences may sometimes be obscured by a ceiling effect limiting response rate.

\section{Future directions: techniques for measuring motivation}

The different techniques have distinct limitations that make them suitable for addressing different research questions and for investigating different resources. For example, a simple, single-motivation choice test can establish a preference amongst unidimensional substitutes, whereas an operant, demand curve approach can measure motivational strength for access to any quantity of a resource whose value is not affected by limiting reward size, and an operant, reservation price approach can estimate the value of a single visit to any resource at a specific deprivation level. Having such a wide array of techniques to choose from is useful, provided the 
techniques are valid and are used appropriately. The critical evaluation of methods in preference and motivation testing is an ongoing process that has run alongside their practical use, but has not always kept pace. A growing number of theoretical papers (Duncan, 1978, 1992; Dawkins, 1980, 1983, 1988, 1990; van Rooijen, 1982; Rushen, 1986a, 1990, 1996; Houston, 1997; Mason et al., 1997, 1998; Kirkden et al., 2003; Jensen et al., 2004d) have recently been complemented by experimental studies aimed primarily at validating methods (Foster et al., 1997; Sumpter et al., 1999; Hansen et al., 2002; Ladewig et al., 2002; Olsson et al., 2002; Pedersen et al., 2002; Sørensen et al., 2001, 2004; Sherwin, 2003; Warburton and Mason, 2003; Jensen et al., 2004a,b), which is an important development. A combination of theoretical and empirical inquiry is leading to more sophisticated thinking about the limitations and appropriate use of existing methods, as well as the development of new approaches. The following methodological issues are currently of interest.

\subsection{Interpretation of demand curves}

Many studies infer the value of a resource from the price elasticity of demand or the slope of the demand curve, following Dawkins $(1983,1988,1990)$ argument that it measures an animal's willingness to defend its consumption of a resource against price rises. A different approach, based on economic theory (Kirkden et al., 2003), infers the value of a specific quantity of a resource at a particular level of prior deprivation or consumption from the reservation price or consumer surplus. It has been argued that the consumer surplus and reservation price have greater internal validity as measures of motivational strength than the price elasticity of demand (Houston, 1997; Kirkden et al., 2003), although empirical support for these arguments is still limited. To date, neither the consumer surplus nor the price elasticity of demand has been experimentally validated. Experimental evidence bearing on the validity of the price elasticity is mixed. Some studies have found that the price elasticity of demand for resources declines (indicating increasing motivational strength) as prior deprivation time increases (e.g., Roper, 1975; Faure and Lagadic, 1994), while others have found that it shows no change (e.g., Meisch and Thompson, 1973; Jensen et al., 2004b,c). Sørensen et al. (2004) reported that the price elasticity of demand ranked quinine solution above distilled water in rats, contrary to the preferences they exhibit in choice tests. The validity of the reservation price has some experimental support. Olsson et al. (2002) showed that the reservation price for food in hens increased with prior food deprivation time, while Cooper and Appleby $(1996,1997)$ found that hens' reservation price for access to a nestbox was greater before oviposition than afterward.

\subsection{Effect of deprivation level on motivation}

It is often assumed that deprivation level does not need to be specified. The price and income elasticities of demand, the reservation price and even the consumer surplus have been used to assign single values to resources. This assumption may be linked to the use of closed economies, in which animals control their own deprivation levels by weighing up motivation against cost. Deprivation is seen as a dependent, not an independent variable (Logan, 1964). Thus, in the elasticity of demand approach, a low elasticity is said to indicate that the animal is highly motivated to avoid deprivation (Dawkins, 1988). However, deprivation is not entirely under the animal's control, except with $24 \mathrm{~h}$ sessions. Furthermore, deprivation level is different at different points on the demand curve. Over the range of prices at which demand is maintained at a relatively high level, the animal is expressing its motivation to avoid mild deprivation, whereas in 
the region where demand is moderate to low, the curve reveals motivation to avoid severe deprivation. This creates a problem, even for the elasticity of demand approach, when the price elasticity of demand is not constant, or when only part of the curve is known. Strategies include manipulating experimental variables in an attempt to obtain demand curves with constant elasticity (Jensen et al., 2004b,c), specifying a standard point on the curve at which to measure price elasticity, $P_{\max }$ (Hursh et al., 1988; Sumpter et al., 1999; Patterson-Kane et al., 2002), or measuring motivation at specific deprivation or prior consumption levels, using the reservation price or consumer surplus (Kirkden et al., 2003; Warburton and Mason, 2003; Kirkden and Pajor, in press). It has been argued that the last approach increases the external validity and versatility of the results (Kirkden et al., 2003).

\subsection{Control of reward size}

Restricting reward size can devalue some resources. However, when animals are given control of reward size, they sometimes take larger rewards when cost is high without paying more, invalidating the demand curve approach (Mason et al., 1997, 1998). Some researchers routinely restrict reward size (e.g., Ladewig and Matthews, 1996), while others prefer to give the animal control (e.g., Sherwin and Nicol, 1995, 1998). Each strategy is effective only for some resources. One solution is to give the animal control, then to use the demand curve approach if reward size does not vary with price and the reservation price index if it does (e.g., Cooper and Mason, 2001; Hovland et al., in press).

\subsection{Effect of reward size and response type on demand curves}

When reward size is controlled, different reward sizes can produce different demand curves (Jensen et al., 2004b,c), even for resources such as food (Hursh et al., 1988) where a small reward size does not interfere with consummation. Likewise, different response types or force requirements can produce different demand curves (Hursh et al., 1988; Sumpter et al., 1999; Hansen et al., 2002). These factors appear to be confounds, but there is evidence that animals respond to them in a rational way and that a unit price analysis, in which reward size and response effort are incorporated into measures of demand and price, can unify demand curves (Hursh et al., 1988; DeGrandpre et al., 1993; Sumpter et al., 1999; Madden et al., 2000).

\subsection{Out of sight, out of mind}

Warburton and Mason (2003) have shown that motivation for access to some resources is increased when animals are exposed to resource cues while responding. They argued that exposure to resource cues is appropriate if the study is designed to measure the pleasure gained from making a resource available, but not if it is attempting to estimate the level of need for access to a resource when it is unavailable.

In practice, it may not be possible to eliminate all cues from some resources, whereas conditioned stimuli are always unavoidable. Thus, motivation tests will tend to overestimate the need for resources and may perhaps, if out of sight is out of mind, even indicate that a motivation exists where none does. Methods to address this problem include minimising exposure to resource cues (Warburton and Mason, 2003), ascertaining whether motivation is influenced by deprivation level (Widowski and Duncan, 2000), and looking for signs of deprivation or frustration when the resource is unavailable (e.g., Mason et al., 2001). 


\subsection{Response-reinforcer compatibility}

It has been argued that animals may find it more difficult to associate certain operant responses with access to some resources than others, thus biasing measures of motivation and preference (Dawkins and Beardsley, 1986). Some operant tasks, such as key pecking in birds, could be problematic because they incorporate elements of feeding or drinking behaviour (Moore, 1973). However, the extent to which these responses are a problem when used in appetence tests is unknown and some researchers use tasks of this kind (e.g., Savory and Duncan, 1982; Faure, 1986; Gunnarsson et al., 2000). In contrast, others prefer to use responses that do not resemble a particular appetitive behaviour, such as pushing through a weighted door, or squeezing through a narrow gap (e.g., Petherick and Rutter, 1990; Sherwin and Nicol, 1995). In aversion testing, there is evidence that animals find it easier to learn passive avoidance responses than active responses to avoid frightening stimuli that would normally cause freezing (Rutter and Duncan, 1991, 1992). It has been suggested that active responses might be more readily learned for avoidance of frustrating stimuli (Rutter and Duncan, 1992).

\subsection{Testing animals in groups}

It has been found that social isolation can influence measures of motivation (Pedersen et al., 2002; Sherwin, 2003). Motivation tests have generally tested animals in isolation, due to the practical difficulties of distinguishing responses made by different subjects and ensuring that the correct subjects are rewarded. However, several recent studies have succeeded in testing individuals in a group context (Sherwin, 2003, 2004).

\section{Conclusions}

Techniques for the assessment of motivation are still under development. Standard approaches have been worked out for the assessment of simple preferences between substitutes (e.g., Blom et al., 1995) and some aversion testing procedures are well established (e.g., Pajor et al., 2000, 2003), but much work still needs to be done on the refinement and validation of methods for the measurement of motivational strength. Nevertheless, with the increasing number of studies that are focusing on methodology, there is reason to expect significant developments and perhaps some movement towards a consensus.

The use of motivation and preference tests to investigate feelings is a very important technique for the assessment of animal welfare. It has both strengths and weaknesses compared with other approaches and should be used in conjunction with these methods to provide information that they cannot. The relative merits of motivation and preference tests versus measures of deprivation or frustration have already been discussed. It is also important to complement motivation and preference tests with an assessment of the health consequences of allowing animals to obtain or avoid things, since there are some situations in which an animal's preferences and priorities are not good for it in the long-term (van Rooijen, 1982; Duncan, 1992).

Provided that preference and motivation tests are carefully interpreted, they have many strengths compared with other approaches. First, they allow animals to express their own priorities, giving us the most direct insight into what is important to them (Dawkins, 1988, 1990). Second, preference and motivation tests are highly sensitive to differences between treatments (Rushen, 1996). Third, some tests are easy to interpret (Rushen, 1996). Fourth, single-motivation appetence tests and aversion tests are quick to carry out, although between-motivations 
appetence tests can be very time-consuming. Fifth, methods designed to measure the strength of motivation are able to ascertain whether a deprivation or aversive stimulus is severe enough to cause suffering (Dawkins, 1988, 1990) and to map out the effects of varying levels of resource provision upon welfare (Kirkden et al., 2003). Sixth, aversion tests are capable of comparing widely different treatments (Rushen, 1996), although there may be difficulty in assessing treatments that affect memory (Rushen, 1990) or motor performance, such as stunning techniques. Seventh, measures of preference and motivation reflect how an animal feels about an environment as a whole and can estimate the net value of an environment that contains both positive and negative stimuli, such as a group pen that offers space and social contact but also competition for resources (Kirkden and Pajor, in press). Alternatively, if the stimuli in the environment are carefully controlled, preference and motivation tests can be used to evaluate individual features of the environment (Fraser and Matthews, 1997).

\section{Acknowledgements}

We thank David Fraser, Georgia Mason, Emily Patterson-Kane and John Webster for their helpful comments on the manuscript.

\section{References}

Abeyesinghe, S.M., Wathes, C.M., Nicol, C.J., Randall, J.M., 2001a. The aversion of broiler chickens to concurrent vibrational and thermal stressors. Appl. Anim. Behav. Sci. 73, 199-215.

Abeyesinghe, S.M., Nicol, C.J., Wathes, C.M., Randall, J.M., 2001b. Development of a raceway method to assess aversion of domestic fowl to concurrent stressors. Behav. Process. 56, 175-194.

Arey, D.S., 1992. Straw and food as reinforcers for prepartal sows. Appl. Anim. Behav. Sci. 33, $217-226$.

Baldwin, B.A., Start, I.B., 1981. Sensory reinforcement and illumination preference in sheep and calves. Proc. R. Soc. Lond. Ser. B 211, 513-526.

Baldwin, J.M. (Ed.), 1901. Dictionary of Philosophy and Psychology. Macmillan, New York.

Berridge, K.C., 1996. Food reward: brain substrates of wanting and liking. Neurosci. Biobehav. Rev. 20, 1-25.

Blom, H.J.M., van Tintelen, G., Baumans, V., van den Broek, J., Beynen, A.C., 1995. Development and application of a preference test system to evaluate housing conditions for laboratory rats. Appl. Anim. Behav. Sci. 43, 279-290.

Broom, D.M., 1998. Welfare, stress and the evolution of feelings. In: Møller, A.P., Milinski, M., Slater, P.J.B. (Eds.), Advances in the Study of Behavior, vol. 27. Academic Press, New York, pp. 371-403.

Burkhardt Jr., R.W., 1997. The founders of ethology and the problem of animal subjective experience. In: Dol, M., Kasanmoentalib, S., Lijmbach, S., Rivas, E., van den Bos, R. (Eds.), Animal Consciousness and Animal Ethics. Van Gorcum, Assen, The Netherlands, pp. 1-13.

Cabanac, M., 1979. Sensory pleasure. Q. Rev. Biol. 54, 1-29.

Cabanac, M., 1992. Pleasure: the common currency. J. Theor. Biol. 155, 173-200.

Cacioppo, J.T., Berntson, G.G., 1999. The affect system: architecture and operating characteristics. Curr. Direct. Psychol. Sci. 8, 133-137.

Cooper, J.J., Appleby, M.C., 1996. Demand for nest boxes in laying hens. Behav. Process. 36, 171-182.

Cooper, J.J., Appleby, M.C., 1997. Motivational aspects of individual variation in response to nestboxes by laying hens. Anim. Behav. 54, 1245-1253.

Cooper, J., Mason, G., Raj, M., 1998. Determination of the aversion of farmed mink (Mustela vison) to carbon dioxide. Vet. Rec. 143, 359-361.

Cooper, J.J., Mason, G.J., 2001. The use of operant technology to measure behavioral priorities in captive animals. Behav. Res. Methods Instrum. Comput. 33, 427-434.

Dawkins, M.S., 1977. Do hens suffer in battery cages? Environmental preference and welfare. Anim. Behav. 25, 10341046.

Dawkins, M.S., 1980. Animal Suffering: The Science of Animal Welfare. Chapman and Hall, London, UK.

Dawkins, M.S., 1983. Battery hens name their price: consumer demand theory and the measurement of ethological "needs". Anim. Behav. 31, 1195-1205. 
Dawkins, M.S., 1988. Behavioural deprivation: a central problem in animal welfare. Appl. Anim. Behav. Sci. 20, 209225.

Dawkins, M.S., 1990. From an animal's point of view: motivation, fitness, and animal welfare. Behav. Brain Sci. 13, 1-61.

Dawkins, M.S., 1993. Through Our Eyes Only? The Search for Animal Consciousness. W.H. Freeman, Oxford, UK.

Dawkins, M.S., Beardsley, T., 1986. Reinforcing properties of access to litter in hens. Appl. Anim. Behav. Sci. 15, 351364.

DeGrandpre, R.J., Bickel, W.K., Hughes, J.R., Layng, M.P., Badger, G., 1993. Unit price as a useful metric in analyzing effects of reinforcer magnitude. J. Exp. Anal. Behav. 60, 641-666.

Duncan, I.J.H., 1970. Frustation in the fowl. In: Freeman, B.M., Gordon, R.F. (Eds.), Aspects of Poultry Behaviour. British Poultry Science Ltd., Edinburgh, UK, pp. 15-31.

Duncan, I.J.H., 1978. The interpretation of preference tests in animal behaviour. Appl. Anim. Ethol. 4, 197-200.

Duncan, I.J.H., 1992. Measuring preferences and the strength of preferences. Poult. Sci. 71, 658-663.

Duncan, I.J.H., 1996. Animal welfare defined in terms of feelings. Acta Agric. Scand. Sect. A Anim. Sci. Suppl. 27, 2935.

Dussault, C., 1996. Behavioural feedback to risk variation ensues from unsatisfied appetency. Accid. Anal. Prevent. 28, $477-486$.

Faure, J.M., 1986. Operant determination of cage and feeder size requirements of the laying hen. Appl. Anim. Behav. Sci. $15,325-336$.

Faure, J.M., Lagadic, H., 1994. Elasticity of demand for food and sand in laying hens subjected to variable wind speed. Appl. Anim. Behav. Sci. 42, 49-59.

Foster, T.M., Temple, W., Cameron, B., Poling, A., 1997. Demand curves for food in hens: similarity under fixed-ratio and progressive-ratio schedules. Behav. Process. 39, 177-185.

Fraser, A.F., Broom, D.M., 1990. Farm Animal Behaviour and Welfare, third ed. Ballière Tindall, London, UK.

Fraser, D., 1985. Selection of bedded and unbedded areas by pigs in relation to environmental temperature and behaviour. Appl. Anim. Behav. Sci. 14, 117-126.

Fraser, D., 1999. Animal ethics and animal welfare science: bridging the two cultures. Appl. Anim. Behav. Sci. 65, 171189.

Fraser, D., Duncan, I.J.H., 1998. 'Pleasures', 'pains' and animal welfare: toward a natural history of affect. Anim. Welfare 7, 383-396.

Fraser, D., Matthews, L.R., 1997. Preference and motivation testing. In: Appleby, M.C., Hughes, B.O. (Eds.), Animal Welfare. CAB International, Wallingford, UK, pp. 159-173.

Fraser, D., Weary, D.M., Pajor, E.A., Milligan, B.N., 1997. A scientific conception of animal welfare that reflects ethical concerns. Anim. Welfare 6, 187-205.

Gable, S.L., Reis, H.T., Elliot, A.J., 2003. Evidence for bivariate systems: an empirical test of appetition and aversion across domains. J. Res. Personal. 37, 349-372.

Gilman, D.P., Westbrook, W.H., 1978. Mating preference and sexual reinforcement in female rats. Physiol. Behav. 20, 1114.

Griffin, D.R., 1976. The Question of Animal Awareness: Evolutionary Continuity of Mental Experience. Rockefeller Press, New York.

Gunnarsson, S., Matthews, L.R., Foster, T.M., Temple, W., 2000. The demand for straw and feathers as litter substrates by laying hens. Appl. Anim. Behav. Sci. 65, 321-330.

Hansen, S.W., Jensen, M.B., Pedersen, L.J., Munksgaard, L., Ladewig, J., Matthews, L., 2002. The type of operant response affects the slope of the demand curve for food in mink. Appl. Anim. Behav. Sci. 76, 327-338.

Hargreaves, A.L., Hutson, G.D., 1990. The effect of gentling on heart rate, flight distance and aversion of sheep to a handling procedure. Appl. Anim. Behav. Sci. 26, 243-252.

Herrnstein, R.J., 1977. The evolution of behaviorism. Am. Psychol. 32, 593-603.

Hogan, J.A., Roper, T.J., 1978. A comparison of the properties of different reinforcers. In: Rosenblatt, J., Hinde, R., Beer, C., Busnel, M.-C. (Eds.), Advances in the Study of Behavior, vol. 8. Academic Press, New York, pp. $155-255$.

Holm, L., Jensen, M.B., Jeppesen, L.L., 2002. Calves' motivation for acces to two different types of social contact measured by operant conditioning. Appl. Anim. Behav. Sci. 79, 175-194.

Houston, A.I., 1997. Demand curves and welfare. Anim. Behav. 53, 983-990.

Hovland, A.L., Mason, G.J., Bøe, K.E., Steinheim, G., Bakken, M. Evaluation of the 'maximum price paid' as an index of motivational strength for farmed silver foxes (Vulpes vulpes). Appl. Anim. Behav. Sci., in press.

Hughes, B.O., 1975. Spatial preference in the domestic hen. Br. Vet. J. 131, 560-564.

Hughes, B.O., Black, A.J., 1973. The preference of domestic hens for different types of battery cage floor. Br. Poult. Sci. 14, 615-619. 
Hursh, S.R., Raslear, T.G., Shurtleff, D., Bauman, R., Simmons, L., 1988. A cost-benefit analysis of demand for food. J. Exp. Anal. Behav. 50, 419-440.

Hutson, G.D., 1985. The influence of barley rewards on sheep movement through a handling-system. Appl. Anim. Behav. Sci. 14, 263-273.

Hutson, G.D., 1989. Do sows need straw for nest-building? Aust. J. Exp. Agric. 28, 187-194.

Jensen, M.B., Tuomisto, L., Pedersen, L.J., 2004a. Locomotor behaviour in dairy calves, the use of demand functions to assess the effect of deprivation. Appl. Anim. Behav. Sci. 86, 3-14.

Jensen, M.B., Munksgaard, L., Pedersen, L.J., Ladewig, J., Matthews, L., 2004b. Prior deprivation and reward duration affect the demand function for rest in dairy heifers. Appl. Anim. Behav. Sci. 88, 1-11.

Jensen, M.B., Pedersen, L.J., Munksgaard, L., 2004c. The effect of reward duration on demand functions for rest in dairy heifers and lying requirements as measured by demand functions. Appl. Anim. Behav. Sci. 90, $207-217$.

Jensen, M.B., Pedersen, L.J., Ladewig, J., 2004d. The use of demand functions to assess behavioural priorities in farm animals. Anim. Welfare 13, S27-S32.

Jezierski, T., Scheffler, N., Bessei, W., Schumacher, E., 2005. Demand functions for cage size in rabbits selectively bred for high and low activity in open-field. Appl. Anim. Behav. Sci. 93, 323-339.

Jones, J.B., Burgess, L.R., Webster, A.J.F., Wathes, C.M., 1996. Behavioural responses of pigs to atmospheric ammonia in a chronic choice test. Anim. Sci. 63, 437-445.

Jones, J.B., Wathes, C.M., Webster, A.J.F., 1998. Operant responses of pigs to atmospheric ammonia. Appl. Anim. Behav. Sci. 58, 35-47.

Jones, J.B., Wathes, C.M., Webster, A.J.F., 1999. Trade off between ammonia exposure and thermal comfort and the influence of social contact in pigs. Anim. Sci. 68, 387-398.

Kirkden, R.D., Pajor, E.A. Motivation for group housing in gestating sows. Anim. Welfare, in press.

Kirkden, R.D., Edwards, J.S.S., Broom, D.M., 2003. A theoretical comparison of the consumer surplus and the elasticities of demand as measures of motivational strength. Anim. Behav. 65, 157-178.

Konorski, J., 1967. Integrative Activity of the Brain: An Interdisciplinary Approach. University of Chicago Press, Chicago, IL.

Ladewig, J., Matthews, L.R., 1996. The role of operant conditioning in animal welfare research. Acta Agric. Scand. Sect. A Anim. Sci. Suppl. 27, 64-68.

Ladewig, J., Sørensen, D.B., Nielsen, P.P., Matthews, L.R., 2002. The quantitative measurement of motivation: generation of demand functions under open versus closed economies. Appl. Anim. Behav. Sci. 79, 325-331.

Lang, P.J., Bradley, M.M., Cuthbert, B.N., 1990. Emotion, attention, and the startle reflex. Psychol. Rev. 97, $377-395$.

Lawrence, A.B., Appleby, M.C., Illius, A.W., MacLeod, H.A., 1989. Measuring hunger in the pig using operant conditioning: the effect of dietary bulk. Anim. Prod. 48, 213-220.

Lea, S.E.G., 1978. The psychology and economics of demand. Psychol. Bull. 85, 441-466.

Logan, F.A., 1964. The free behavior situation. In: Leine, D. (Ed.), Nebraska Symposium on Motivation, vol. 12, University of Nebraska Press, Lincoln, NE, pp. 99-134.

Madden, G.J., Bickel, W.K., Jacobs, E.A., 2000. Three predictions of the economic concept of unit price in a choice context. J. Exp. Anal. Behav. 73, 45-64.

Manser, C.E., Elliott, H., Morris, T.H., Broom, D.M., 1996. The use of a novel operant test to determine the strength of preference for flooring in laboratory rats. Lab. Anim. 30, 1-6.

Mason, G.J., Cooper, J.J., Garner, J., 1997. Models of motivational decision-making and how they affect the experimental assessment of motivational priorities. In: Forbes, J.M., Lawrence, T.L.J., Rodway, R.G., Varley, M.A. (Eds.), Animal Choices. British Society for Animal Science, Penicuik, Midlothian, pp. 9-17.

Mason, G.J., McFarland, D., Garner, J., 1998. A demanding task: using economic techniques to assess animal priorities. Anim. Behav. 55, 1071-1075.

Mason, G.J., Cooper, J.J., Clarebrough, C., 2001. Frustrations of fur-farmed mink. Nature 410, 35-36.

Masterson, F.A., Crawford, M., 1982. The defense motivation system: a theory of avoidance behavior. Behav. Brain Sci. 5, 661-696.

Matthews, L.R., 1998. Using economic techniques to assess animal priorities: repays the investment. Anim. Behav. 55, 1076-1078.

Matthews, L.R., Chandler, J.H., 1996. Assessing behavioural demand functions: issues. In: Duncan, I.J.H., Widowski, T.M., Haley, D.B. (Eds.), Proceedings of the 30th International Congress of the International Society for Applied Ethology, Guelph, Ontario, Canada. Col. K.L. Campbell Centre for the Study of Animal Welfare, University of Guelph, Guelph, Canada, 14-17 August, p. 54.

Matthews, L.R., Ladewig, J., 1994. Environmental requirements of pigs measured by behavioural demand functions. Anim. Behav. 47, 713-719. 
Matthews, L.R., Temple, W., Foster, T.M., McAdie, T.M., 1993. Quantifying the environmental requirements of layer hens by behavioural demand functions. In: Nichelmann, M., Wierenga, H.K., Braun, S. (Eds.), Third Joint Meeting, International Congress on Applied Ethology, KTBL, Berlin, Germany, pp. 206-209.

Matthews, L.R., Temple, W., Foster, T.M., Walker, J., McAdie, T.M., 1995. Comparison of the demand for dustbathing substrates by layer hens. In: Rutter, S.M., Rushen, J., Randle, H.D., Eddison, J.C. (Eds.), Proceedings of the 29th International Congress of the International Society for Applied Ethology, Exeter, UK. Universities Federation for Animal Welfare, Potters Bar, UK, 3-5 August, pp. 11-12.

Matthews, L.R., Walker, J., Foster, T.M., Temple, W., 1998. Influence of reward magnitude on elasticity of demand for dustbathing in hens. In: Veissier, I., Boissy, A. (Eds.), Proceedings of the 32nd International Congress of the International Society for Applied Ethology, Institut National de la Recherche Agronomique (INRA), ClermontFerrand, France, p. 86.

Meisch, R.A., Thompson, T., 1973. Ethanol as a reinforcer: effects of fixed ratio size and food deprivation. Psychopharmacologia 28, 171-183.

Moore, B.R., 1973. The role of directed Pavlovian reactions in simple instrumental learning in the pigeon. In: Hinde, R.A., Stevenson-Hinde, J. (Eds.), Constraints on Learning: Limitations and Predispositions. Academic Press, London, UK, pp. 159-186.

Nicol, C.J., 1986. Non-exclusive spatial preference in the laying hen. Appl. Anim. Behav. Sci. 15, 337-350.

Nicol, C.J., 1997. Environmental choices of farm animals. In: Forbes, J.M., Lawrence, T.L.J., Rodway, R.G., Varley, M.A. (Eds.), Animal Choices. British Society for Animal Science, Penicuik, UK, pp. 35-43.

Olsson, I.A.S., Keeling, L.J., McAdie, T.M., 2002. The push-door for measuring motivation in hens: an adaptation and a critical discussion of the method. Anim. Welfare 11, 1-10.

Pajor, E.A., Rushen, J., de Passillé, A.M., 2000. Aversion learning techniques to evaluate dairy cattle handling practices. Appl. Anim. Behav. Sci. 69, 89-102.

Pajor, E.A., Rushen, J., de Passillé, A.M., 2003. Dairy cattle's choice of handling in a Y-maze. Appl. Anim. Behav. Sci. 80, 93-107.

Patterson-Kane, E.G., Hunt, M., Harper, D., 2002. Rats demand social contact. Anim. Welfare 11, 327-332.

Pedersen, L.J., Jensen, M.B., Hansen, S.W., Munksgaard, L., Ladewig, J., Matthews, L., 2002. Social isolation affects the motivation to work for food and straw in pigs as measured by operant conditioning techniques. Appl. Anim. Behav. Sci. 77, 295-309.

Petherick, J.C., Rutter, S.M., 1990. Quantifying motivation using a computer-controlled push-door. Appl. Anim. Behav. Sci. 27, 159-167.

Petherick, J.C., Duncan, I.J.H., Waddington, D., 1990a. Previous experience with different floors influences choice of peat in a Y-maze by domestic fowl. Appl. Anim. Behav. Sci. 27, 177-182.

Petherick, J.C., Waddington, D., Duncan, I.J.H., 1990b. Learning to gain access to a foraging and dustbathing substrate by domestic fowl: is 'out of sight out of mind?'. Behav. Process. 22, 213-226.

Petherick, J.C., Sutherland, R.H., Waddington, D., Rutter, S.M., 1992. Measuring the motivation of domestic fowl in response to a positive and a negative reinforcer. Appl. Anim. Behav. Sci. 33, 357-366.

Phillips, C.J.C., Morris, I.D., 2001. A novel operant conditioning test to determine whether dairy cows dislike passageways that are dark or covered with excreta. Anim. Welfare 10, 65-72.

Raj, A.B.M., Gregory, N.G., 1991. Preferential feeding behaviour of hens in different gaseous atmospheres. Br. Poult. Sci. 32, 57-65.

Raj, M., Mason, G., 1999. Reaction of farmed mink (Mustela vison) to argon-induced hypoxia. Vet. Rec. 145, 736-737.

Randall, J.M., Duggan, J.A., Alami, M.A., White, R.P., 1997. Frequency weightings for the aversion of broiler chickens to horizontal and vertical vibration. J. Agric. Eng. Res. 68, 387-397.

Rollin, B.E., 1990. The Unheeded Cry. Oxford University Press, Oxford, UK.

Roper, T.J., 1975. Nest material and food as reinforcers for fixed-ratio responding in mice. Learn. Motiv. 6, 327-343.

Rushen, J., 1986a. The validity of behavioural measures of aversion: a review. Appl. Anim. Behav. Sci. 16, 309-323.

Rushen, J., 1986b. Aversion of sheep for handling treatments: paired-choice studies. Appl. Anim. Behav. Sci. 16, 363370.

Rushen, J., 1990. Use of aversion-learning techniques to measure distress in sheep. Appl. Anim. Behav. Sci. $28,3-14$.

Rushen, J., 1996. Using aversion learning techniques to assess the mental state, suffering, and welfare of farm animals. J. Anim. Sci. 74, 1990-1995.

Rushen, J., Congdon, P., 1987. Electro-immobilisation of sheep may not reduce the aversiveness of a painful treatment. Vet. Rec. 120, 37-38.

Rutter, S.M., Duncan, I.J.H., 1991. Shuttle and one-way avoidance as measures of aversion in the domestic fowl. Appl. Anim. Behav. Sci. 30, 117-124. 
Rutter, S.M., Duncan, I.J.H., 1992. Measuring aversion in domestic fowl using passive avoidance. Appl. Anim. Behav. Sci. 33, 53-61.

Savory, C.J., Duncan, I.J.H., 1982. Voluntary regulation of lighting by domestic fowls in Skinner boxes. Appl. Anim. Ethol. 9, 73-81.

Sherwin, C.M., 1996. Laboratory mice persist in gaining access to resources: a method of assessing the importance of environmental features. Appl. Anim. Behav. Sci. 48, 203-214.

Sherwin, C.M., 1999. Domestic turkeys are not averse to compact fluorescent lighting. Appl. Anim. Behav. Sci. 64, 47-55.

Sherwin, C.M., 2003. Social context affects the motivation of laboratory mice, Mus musculus, to gain access to resources. Anim. Behav. 66, 649-655.

Sherwin, C.M., 2004. The motivation of group-housed laboratory mice, Mus musculus, for additional space. Anim. Behav. 67, 711-717.

Sherwin, C.M., Nicol, C.J., 1995. Changes in meal patterning by mice measure the cost imposed by natural obstacles. Appl. Anim. Behav. Sci. 43, 291-300.

Sherwin, C.M., Nicol, C.J., 1996. Reorganisation of behaviour in laboratory mice, Mus musculus, with varying cost of access to resources. Anim. Behav. 51, 1087-1093.

Sherwin, C.M., Nicol, C.J., 1997. Behavioural demand functions of caged laboratory mice for additional space. Anim. Behav. 53, 67-74.

Sherwin, C.M., Nicol, C.J., 1998. A demanding task: using economic techniques to assess animal priorities. A reply to Mason et al. Anim. Behav. 55, 1079-1081.

Sørensen, D.B., Ladewig, J., Matthews, L., Ersbøll, A.K., Lawson, L., 2001. Measuring motivation: using the cross point of two demand functions as an assessment of the substitutability of two reinforcers. Appl. Anim. Behav. Sci. 74, 281291.

Sørensen, D.B., Ladewig, J., Ersbøll, A.K., Matthews, L., 2004. Using the cross point of demand functions to assess animal priorities. Anim. Behav. 68, 949-955.

Steiger, A., Tschanz, B., Jacob, P., Scholl, E., 1979. Verhaltensuntersuchungen bei Mastschweinen auf verschiedenen Bodenbelagen und bei verschiedener Besatzdichte. Schweiz. Arch. Tierheilkd. 121, 109-126.

Stephens, D.B., Bailey, K.J., Sharman, D.F., Ingram, D.L., 1985. An analysis of some behavioural effects of the vibration and noise components of transport in pigs. Q. J. Exp. Physiol. 70, 211-217.

Sumpter, C.E., Temple, W., Foster, T.M., 1999. The effects of differing response types and price manipulations on demand measures. J. Exp. Anal. Behav. 71, 329-354.

Tinbergen, N., 1951. The Study of Instinct. Clarendon Press, Oxford, UK.

Toates, F., 1986. Motivational Systems. Cambridge University Press, Cambridge, UK.

Toates, F., 1987. The relevance of models of motivation and learning to animal welfare. In: Wiepkema, P.R., van Adrichem, P.W.M. (Eds.), Biology of Stress in Farm Animals: An Integrative Approach. Martinus Nijhoff, Dordrecht, The Netherlands, pp. 153-186.

van Rooijen, J., 1982. The value of choice tests in assessing welfare of domestic animals. Appl. Anim. Ethol. 8, $295-299$.

Varian, H.R., 1996. Intermediate Microeconomics: A Modern Approach, fourth ed. W.W. Norton, New York.

Warburton, H.J., Mason, G.J., 2003. Is out of sight, out of mind? The effects of resource cues on motivation in the mink (Mustela vison). Anim. Behav. 65, 755-762.

Warburton, H.J., Nicol, C.J., 2001. The relationship between behavioural priorities and animal welfare: a test using the laboratory mouse, Mus musculus. Acta Agric. Scand. Sect. A Anim. Sci. Suppl. 30, 124-130.

Widowski, T.M., Duncan, I.J.H., 2000. Working for a dustbath: are hens increasing pleasure rather than reducing suffering? Appl. Anim. Behav. Sci. 68, 39-53.

Young, P.T., 1959. The role of affective processes in learning and motivation. Psychol. Rev. 66, 104-125. 